\title{
Coexistent ulcerative colitis and Crohn's disease
}

\author{
B.J.M. Jones ${ }^{1}$, S.R. Gould* \& D.J. Pollock ${ }^{2}$ \\ Departments of ${ }^{I}$ Gastroenterology and ${ }^{2}$ Morbid Anatomy, The London Hospital, London E1 1BB, UK.
}

\begin{abstract}
Summary: This case report describes a patient with chronic ulcerative colitis and epithelial dysplasia of 17 y duration ultimately complicated by colonic carcinoma. At laparotomy, clinically unsuspected but typical Crohn's disease of the terminal ileum was also found. The macroscopic and histological features of the resected terminal ileum were characteristic of Crohn's disease.
\end{abstract}

\section{Introduction}

With one exception (Otani, 1955) early reports of coexistent Crohn's disease and ulcerative colitis lacked sufficient pathological criteria to substantiate the claimed association (Warren \& Sommers, 1954; Counsell, 1956; Colcock \& Vansont, 1961; Edwards \& Truelove, 1964; Evans \& Acheson, 1965; Mendeloff et al., 1966). With the recognition of colonic Crohn's disease and the establishment of clear pathological criteria for Crohn's disease and ulcerative colitis, it has become apparent that the concurrence of these two conditions is extremely rare. In only 3 cases (Voitk et al., 1976; Eyer et al., 1980; White et al., 1983) have the diagnostic criteria been satisfactorily documented. We present a patient with clear pathological evidence of terminal ileal Crohn's disease and longstanding ulcerative colitis with dysplasia culminating in colonic carcinoma.

\section{Case report}

A 30 year old man presented to St Mark's Hospital in 1934 with granular proctitis. In 1942 he developed a perianal abscess but was then lost to follow up until 1959 when he was found to have finger clubbing at another hospital. From 1965 until 1971 his granular proctitis was persistently associated with dysplastic rectal polyps and severe mucosal dysplasia (Figure 1). A barium enema in 1965 revealed a narrow rectosigmoid region, a widened rectosacral space and a paracolic mass. The remaining colon and caecum were normal. He refused surgery and returned in 1975 with

Correspondence: B.J.M. Jones, B.Sc., M.B., B.S., M.R.C.P. Department of Gastroenterology, The London Hospital, Whitechapel, London, E1 1BB.

* Present address: Epsom District Hospital, Dorking Road, Epsom, Surrey. KT18 7EG.

Accepted: 13 December 1984 bloody diarrhoea and histologically active proctitis but no dysplasia. A further barium enema confirmed left sided colitis and suggested a rectal carcinoma which could not be confirmed on sigmoidoscopy. Salazopyrine was introduced. Over the next $2 y$ he complained of post-prandial abdominal pain with alternating constipation and diarrhoea. Rectal biopsies again indicated some improvement in both inflammation and dysplasia. However, in 1980, a mucin secreting adenocarcinoma was detected at $15 \mathrm{~cm}$ and removed by anterior resection. Typical Crohn's disease involving $20 \mathrm{~cm}$ of terminal ileum was also found. A right hemicolectomy was performed with resection of $38 \mathrm{~cm}$ of terminal ileum.

Histology of the sigmoid colon confirmed a diffusely infiltrating mucin secreting adenocarcinoma extending through to surrounding fat and involving local lymph nodes. In the adjacent mucosa there were extensive dysplastic changes but no crypt abscesses. The caecum and resected right colon showed abnormal mucosa with irregular gland pattern, goblet cell

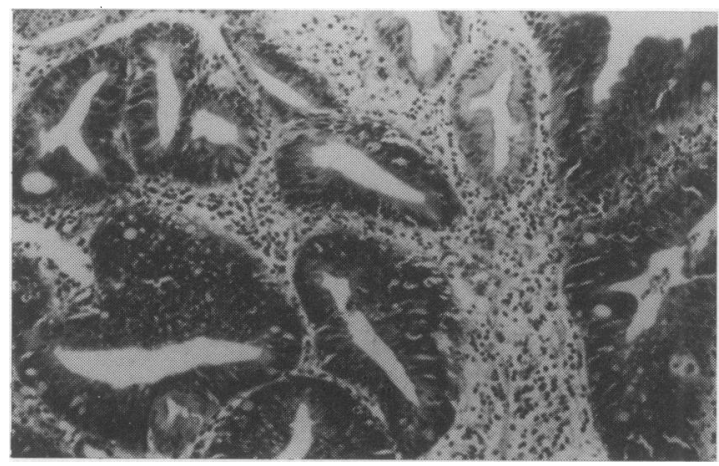

Figure 1 Rectal biopsy in 1969 showing dysplastic mucosa. (H \& E × 100)

(C) The Fellowship of Postgraduate Medicine, 1985 
depletion and patchy dysplasia but no crypt abscesses or inflammation beyond the submucosa. These changes indicated ulcerative colitis in a late stage and were not those of colonic Crohn's disease. The terminal ileum was narrowed by submucosal fibrosis and fissuring ulcers penetrated deep into its wall (Figure 2). Although no granulomata were found, collections of lymphocytes were present in the submucosa and muscle coats. These findings were typical of Crohn's disease. Late in 1980, he underwent pan-proctocolectomy for persistent bloody diarrhoea unresponsive to medical treatment. The colon, ileum, rectal remnant and mesentery were extensively infiltrated by mucin secreting adenocarcinoma. Throughout the colon and rectum there were extensive dysplastic changes but where these were absent there was goblet cell depletion and irregular gland pattern but no crypt abscesses.

The patient died in 1982, aged seventy-nine, $48 \mathrm{y}$ after his first symptoms of colitis and $17 \mathrm{y}$ after the initial detection of mucosal dysplasia.

\section{Discussion}

We have described a patient who had both terminal ileal Crohn's disease and ulcerative colitis. The ileal lesion had not been apparent clinically but showed the typical appearances of Crohn's disease at laparotomy. The histology was characteristic of Crohn's disease with transmural inflammation and deep fissures. The appearance was not that of a back-wash ileitis (Counsell, 1956). Radiologically and at operation the colitis appeared to be distal involving the rectum and sigmoid colon, although histologically there were more extensive changes indicating a pan-colitis. The microscopic changes were those of an ulcerative colitis and not those of Crohn's disease.

The patient described here therefore illustrates the extremely rare coexistence of both Crohn's disease and ulcerative colitis. With the possible exception of the report by Otani (1955) early reports of coexistent ulcerative colitis and Crohn's disease lacked sufficient pathological detail to permit substantiation of the claimed association (Warren \& Sommers, 1954; Counsell, 1956; Colcock \& Vansont, 1961; Edwards \& Truelove, 1964; Evans \& Acheson, 1965; Mendeloff $e t$ $a l ., 1966)$. These reports pre-dated the general recognition of colonic Crohn's disease and in reviewing the features of this condition in a large series from St Mark's Hospital, Lockhart-Mummery \& Morson (1964) stated that they had never seen ulcerative colitis and Crohn's disease in the same patient.

The nature of the colonic lesion of the patient with Crohn's disease described by Schima (1970) must be in doubt owing to the difficulty in classifying fulminant colitis histologically (Price, 1978). More recently, however, Voitk et al. (1976), Eyer et al. (1980) and

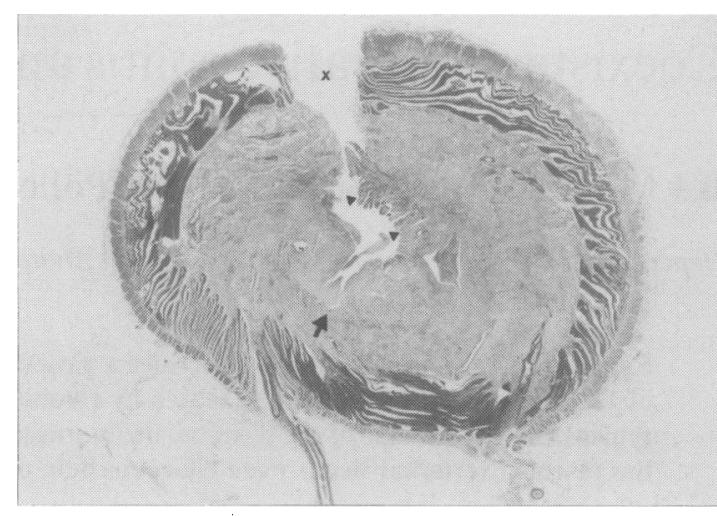

Figure 2 Low power view of a cross-section of the terminal ileum. There is gross distortion of the mucosa best seen in the area between the small arrow heads with thickening of the mucosa and submucosa. the muscularis mucosa is indicated by the large arrow and here a fissure is seen. The large full thickness fissure marked ' $\mathrm{X}$ ' is an artefact. (H \& E × 4)

White et al. (1983) have each described a patient in whom there was good clinical and pathological evidence that ulcerative colitis and Crohn's disease can coexist. This patient confirms their observations.

Crohn's disease and ulcerative colitis are perhaps polar manifestations of a single pathological proces but the calculated rate of coincidence of each condi tion considerably exceeds the number of reported cases (Eyer et al., 1980). This suggests that the two diseases are distinct entities (White et al., 1983) although the occurrence of epithelial dysplasia and carcinoma in Crohn's colitis (Craft et al., 1981; Simpson et al., 1981) suggests a common response by the large bowel mucosa to chronic inflammation.

The long survival of this patient, $17 \mathrm{y}$ after the first demonstration of dysplasia, and his subsequent death from colonic carcinoma, illustrate that the natural history of colitis related dysplasia may be protracted. To the best of our knowledge this is the longest documented interval between the recognition of dysplasia and the subsequent development of carcinoma. Furthermore, these changes occurred despite radiologically distal colitis. These observations add further to the dilemmas surrounding the long term management of these patients (Lennard-Jones et al., 1983).

\section{Acknowledgements}

We should like to thank Professor J.E. Lennard-Jones for permission to report this patient who was under his care and for his helpful criticism during the preparation of this paper. We are grateful to Mrs Barbara Hunt for secretarial assistance. 


\section{References}

COLCOCK, B.P. \& VANSONT, J.H. (1961). Surgical treatment of coexisting regional enteritis and ulcerative colitis. Surgery, Gynecology and Obstetrics, 112, 96.

COUNSELL, B. (1956). Lesions of the ileum associated with ulcerative colitis. British Journal of Surgery, 44, 276.

CRAFT, C.F., MENDELSOHN, G., COOPER, H.S. \& YARDLEY, J.G. (1981). Colonic "precancer" in Crohn's disease. Gastroenterology, 80, 578.

EDWARDS, F.S. \& TRUELOVE, S.C. (1964). The course and prognosis of ulcerative colitis. Part III. Complications. Gut $, \mathbf{5}, 1$.

EVANS, J.G. \& ACHESON, E.D. (1965). An epidemiological study of ulcerative colitis and regional enteritis in the Oxford area. Gut, 6, 311.

EYER, S., SPADACCINI, C., WALKER, P., ANSEL, H., SCHWARTZ, M. \& SUMNER, H.W. (1980). Simultaneous ulcerative colitis and Crohn's disease. American Journal of Gastroenterology, 73, 345.

LENNARD-JONES, J.E., MORSON, B.C., RITCHIE, J.K. \& WILLIAMS, C.B. (1983). Cancer surveillance in ulcerative colitis. Experience over 15 years. Lancet, ii, 149.

LOCKHART-MUMMERY, H.E. \& MORSON, B.S. (1964). Crohn's disease of the large intestine. Gut, 5, 493.

MENDELOFF, A.I., MONK, M., SIEGEL, C.I. \& LILIENFELD,
A. (1966). Some epidemiological features of ulcerative colitis and regional enteritis. Gastroenterology, 51, 748.

OTANI, S. (1955). Pathology of regional enteritis and regional enterocolitis. Journal of the Mount Sinai Hospital, 22, 147.

PRICE, A.B. (1978). Overlap in the spectrum of non-specific inflammatory bowel disease - 'colitis indeterminate'. Journal of Clinical Pathology, 31, 567.

SCHIMA, E. (1970). Coincidence of Crohn's regional enteritis and ulcerative colitis. Münchener medizinische Wochenschrift, 112, 2026.

SIMPSON, S., TRAUBE, J., RIDDELL, R.H. (1981). The histologic appearance of dysplasia (precarcinomatous change) in Crohn's disease of the small and large intestine. Gastroenterology, 81, 492.

VOITK, A.J., OWEN, D.R. \& LOUGH, J. (1976). Coexistent regional enteritis and ulcerative colitis. International Surgery, 61, 535 .

WARREN, S. \& SOMMERS, S.C. (1954). Pathology of regional ileitis and ulcerative colitis. Journal of the American Medical Association, 154, 189.

WHITE, C.L., HAMILTON, S.R., DIAMOND, M.P. \& CAMERON, J.L. (1983). Crohn's disease and ulcerative colitis in the same patient. Gut, 24, 857. 